\title{
Budgeting Beyond Budgeting: A Tool for Management, Surprise Avoidance, Trust Creation and Organizational \\ Learning
}

\author{
Josep Maria Rosanas \\ IESE
}

Received October 29, 2016; accepted November 13, 2016.

\begin{abstract}
While for quite a long time the budget was considered one of the crucial management tools, it has always been subject to criticisms, which have become stronger in the last couple of decades, under the commercial name of "Beyond Budgeting". In this article, we review the history and foundations of budgeting, to show how typically, the criticisms to budgeting have to be addressed to a bad management style, and not to the technique itself. Then, I use an example to show how budgets can be used to the firm's advantage in many fields, but mainly in being able to avoid unpleasant surprises, create trust between the different hierarchical levels of the firm, and enhance learning in the positive sense. This allows the firm to avoid vicious circles that are often found in the practice of budgeting because of bad management, not because of the budgets themselves.
\end{abstract}

\section{KEYWORDS}

Budgeting, management, trust, command and control, management control process. 


\section{Introduction}

Towards the middle of the XX Century, the budget was almost "the" management tool. Nevertheless, at this time, some criticisms about budgeting started to arise already, mainly about the time and effort needed to prepare them and analyze them, and about how to balance different objectives that were pursued with them as well. Already in the $21^{\text {st }}$ Century, and under the name of "beyond budgeting", new proposals to eliminate budgets and replace them with other tools appeared. In spite of that, as we will see, most firms continue to have them.

A matter often neglected in the literature on budgets (both textbooks and academic journals on the one side and in publications for professionals on the other often ignore, or simply tiptoe on the subject is nevertheless crucial. It is the matter of how the budget process takes place within the control process as well as within the organizational climate and management of the organization, which is crucial in order to obtain good results.

This paper aims to analyze some of the problems related with budgeting. Specifically, I intend to argue that: (1) budgets, when they are used rightly, are very useful and, thus, to suppress them is usually a bad decision; (2) if they are understood as a mere technical tool, then they become a mere bureaucratic requirement void of meaning and even harmful; (3) the way management handles the budgetary process is crucial for the process to go one way or another; (4) an important part of the usefulness of the budgetary process rightly done (subject that has received very little attention in both the academic and in the professional literature) derives more from their contribution to the human functioning of the organization than from the objective result of budgets (i.e., the documents containing the financial plans); and, finally (5) that the learning budgeting introduces is even more important perhaps.

I will proceed as follows. First, I will briefly review the history of budgets, to show they are a tool whose use is complex and has many non-technical aspects, possibly conflicting objectives and that have to be based on a contingency approach. Then, I will show the typical objections to budgets, analyze them, and go to describe a summary of an example of the budgetary process of a particular company. I will attempt to show how it can be used right in the context of a reasonable structure and management process, and how it can be misused to become a sterile routine that goes against its own essence and its own objectives. Finally, I will draw some conclusions, both of a conceptual nature and for business practice. 


\section{Development of budgeting and early criticisms: a historical view}

Towards the middle of the 20th Century, budgets were almost the management technique par excellence. To be sure, at the beginning of that Century, there were other management techniques. Taylor and his followers had created many successful ones under the name of "Scientific Management", but all these techniques were rather "partial", having to do with only one specific activity or one aspect of the firm (in general, of a routine or mechanical kind), not as a wholistic technique encompassing the firm in its entirety. Henry Fayol, already in 1916, published a book (in France, which made him less known in the Anglo-Saxon world until the end of the 40's, when a good translation of his book was published) that has had a lot of influence in the management literature. There, he established the five elements (or functions) of management: planning, organizing, commanding, coordinating and controlling that later on became the basis of organization in most introductory textbooks on administration. He did not use the word "budget" (except only once in the context of public administration budgets), but of course the French original word, prévoyance, which is often translated as "planning" as the first of the five elements, has a lot to do with budgeting. In fact, we can see that he intended to go well beyond what later on everybody meant as "budgeting", including the way the planning process should take place. The word prévoyance itself (which could have been translated as "forethought") is closer to suggesting (perhaps even more than planning) that the output of the process should include both a mere forecast of how environmental variables would evolve, and at the same time, an expression of the decisions made by management., which is exactly what a budget should be.

However, the implementation of Fayol's idea into practice did not take place very quickly. According to Hofstede (1968, pp. 20-22), in the US the use of budgets in private firms started in the 1920's with principles clearly derived from the budget technique used in government; and, at the same time, they can be seen as a logical extension of Taylor's Scientific Management (Fayol, at that time, was largely unknown in the US). Large-scale application of budgets started in the 30's, in the Depression years. In 1941, a detailed survey of companies employing a total of 850.000 people, found that roughly $50 \%$ used budgetary control; while in 1958, a different sample of 424 companies found that $95 \%$ of them did. So, the 50's were probably the years in which budgets made a lot of progress. In Europe, there was a time lag of about 10 years with respect to the US (Hofstede, 1968). So, budgeting was a success story in a rather short time after World War II. A basic accounting textbook that become very popular at the time would state that "Management 
primary function is to plan (...) Budgets are the expression, largely in financial terms, of management's plans for operating and financing the enterprise..." (Gordon and Shillinglaw, 1964, Ch. 23). In brief, they are the quantitative expression of management's primary function. Many years later, already in the XXI Century, two well-known researchers, Hansen \& Van der Stede (2004) continued to feel the same way: "budgeting is an important control system in almost all organizations". Therefore, there is no doubt that budget was and still is considered to be, an important management tool or procedure.

\section{Non-technical aspects of budgeting}

Nevertheless, not everybody agreed. From the very beginning, some (positive!) warnings, that were to become criticisms later on, already appeared. The two landmark, managerial (as opposed to merely technical) books that probably contributed more than anyone else to the dissemination of budgets (Dearden, 1962; Hofstede, 1968) already warned that the task of preparing a good budget and then using it for control purposes was not easy. Calling them "general rules" or "axioms", but in a way that sounds like "grandfather's advice", Dearden gives some recommendations about how to prepare budgets and who should do it. For example, that the person preparing the initial budget should be the person responsible for operating under it; or that line personnel should be informed of the plans, objectives and timing of the system, that budget personnel should lean over backward to be scrupulously honest with line personnel, and so on (Dearden, 1962, pp 93-102).

Hofstede (1968) gives a long list of recommendations to put budgets into practice as well, and his use of the word "game" in the title already suggests that budgets are not going to be a straightforward technique with no need for "judgment". This time, his list comes from a clinical study of a limited number of firms; but he recognizes that his recommendations go beyond the strict limits of his findings.

The recommendations embrace all levels of the organization and they are far too long to be summarized; but I will to focus on some of them that are particularly important for the purpose of this paper. For instance, there is a recommendation that is common to all levels of "line" personnel, from tom management to foremen or first-line managers: that the budget system is their tool to manage the company. Consistently, Hofstede tells the controller and budget accountants that the success of a system depends on the line managers, not on themselves; and therefore they must provide assistance and supply the data needed, but the actual figuring of the budget has to be done by line managers (Hofstede, 1968, Ch. 15). Therefore, budgets are a tool, but not merely technical: 
judgment has to be used by the people that do them to make decisions. Hence, using them "right" or using them "poorly" will make a lot of a difference in the results, because of the different reactions that may be elicited from the line people affected. As we will see below, "lying" or "not lying" in the process, and "taking interest in it" or not depends on the way the budgetary process is designed and implemented.

In other words, budgets have to be considered a management activity, and, thus, have to be accepted in managerial terms. One should not expect budgets to be a technique that does not need managerial abilities to be applied, or a technique that works alone automatically, or is done by specialists in accounting and/or finance. On the contrary, it is something that has to be applied by line management, largely by people whose training in accounting is rather limited, as accounting is not their job (like people in production or sales, who typically are a big percentage of the firm's payroll) and thus has to be as simple as possible. Otherwise, one should not be surprised to find most of the people involved to be strongly against budgets. They may simply misunderstand budgets or budgets may require from them an unreasonable effort.

\section{Conflicts in budgeting objectives}

But there is an additional point that is, for our purposes, crucial. It has to do with the raison d'être of budgets. Why do we do budgets at all? One of the essential reasons for criticism at the top management level has always been the ambiguity in the objective to be attained with budgeting. An cursory examination of the books that covered the subject in the 60's and 70's of the past century would show that the frequently found expression "budget control" would suggest that control was the primary objective. Since, as I stated before, budgets were "imported" from public management, the literal translation of them into business practice was to make decisions on how much to spend in every activity or department, and then try to explain the possible variances. Fayol's main purpose (1916) was to foresee what could happen so that, if something "bad" were thought to be likely to occur, actions could be taken to prevent it from happening. This is close to "planning", but fell short of this concept, which was the next step; and, of course, planning and control are the two sides of the same coin (Anthony, 1965) and motivation immediately follows. This triple objective (planning, control and motivation) was explicitly analyzed by Barret and Fraser (1977) in some detail, mainly from a practical point of view, showing how there is some degree of conflict between any two of the three objectives. Thus, a budgetary system cannot emphasize them all at the same time: the priorities should be 
clearly established to avoid fighting in different and disperse directions. Depending on the firm, on the environment, and on the firm's strategy, and (as we will see below) on the Critical Success Factors, it will be wise to emphasize one or another of the three mentioned objectives.

The situation will get more complex if instead of three objectives we consider four or more. Many textbooks add "communication" and "coordination", whose degree of importance depends on the degree of centralization/decentralization with which the firm is governed. At a different level of abstraction, other researchers mention as objectives of budgets "directing management's attention from the present to the future", "enabling managers to anticipate problems in time", "giving managers an ongoing reminder of actions they have agreed to" (Shillinglaw \& Meyer, 1983). Hansen and Van der Stede (2002) have re-examined the issue of multiple objectives more recently. Obviously, many of these objectives are related to each other, but the fact that there may be some degree of conflict remains nevertheless.

\section{The "contingency approach" to management accounting}

An important point in this context is the contingency theory of management accounting (Otley, 1980). This expression, of course, comes from Lawrence and Lorsch (1967), who argued that there is an "important relationship among external variables (the certainty and diversity of the environment, and the strategic environmental issue), internal states of differentiation and integration, and the process of conflict resolution. If an organization's internal states and processes are consistent withe external demands, the findings of this study suggest it will be effective in dealing with its environment". Therefore, "managers can no longer be concerned about the one best way to organize"” (pp. 156-7). Vancil (1973) and Anthony, Dearden \& Vancil (1972) can be said to have applied that to management control systems although they used neither the word contingency nor the names of Lawrence and Lorsch, either in the article or in the book. But what they were saying, in fact, was that before designing measures of the financial responsibility of managers, one has to consider the strategy and structure of the company. Not directly mentioning budgeting as such, they go to the general design of the control system and emphasize that they have to be based on the key economic variables: "an effective system is highly situational" (...) it must be tailored to the specifics of the situation: this company's objectives, this company's business, and this company's managers" (Anthony et al., 1972, chapter 4). 
Furthermore, given the environment, given the product, and given the company's strategy, there are "critical success factors" (CSF) around which the control system has to be centered. Identifying those factors is not easy, and it may take years of better understanding the environment and better redefining the company's strategy. "For a management control system to be effective (...) each characteristic must be thoroughly understood along with its implications for systems effectiveness" and (...) it must identify the CSFs that should receive careful and continuous management attention if the company is to be successful, and must highlight performance with respect to these key variables in reports to all levels of management." (Anthony et al., 1972, chapter 4). This, of course, includes budgets, considered an essential tool in the management control process, in the same line of being an indispensable part of the primary management function of planning, as in the Gordon \& Shillinglaw quote above.

The obvious consequence of the contingency approach (a much better expression than "contingency theory", because rigorously speaking, a contingency theory is no theory at all!) and of the multiple objectives of the budgeting system is that both the budgeting techniques and the budgetary process have to be adapted to all these factors. The budgeting process, thus, is of a non-technical nature and has to be based on the basic management concepts. Therefore, it has to do with the organizational structure and personal interrelationships within the organization. In short, not only there is "no one best way to budget", but also the way to budget in a specific firm at a given point in time depends on many factors, some of them with important elements of subjectivity, namely, the identification of the critical success factors and the strategy that follows.

Subsequent research took a slightly different road, even though the spirit was the same. Thus, Bruns and Waterhouse (1975) showed how there is a clear relationship between organization structure and the use and behavioral effects of budgets providing interesting insights into several complex relationships suggested by other research on control in organizations, and Flamholtz (1983) examined the budgeting practices in the context of a wide concept of management control systems and its relationship with the organizational settings, both in theory and empirically. But in any case, budgeting was not seen as a mere technical device, but as a practice that had to take place in the context of a strategy and critical success factors, and closely related to behavioral considerations. 


\section{Objections to budgets}

Through the years, many objections have been formulated to budgets, often because of problems that have arisen due to not paying enough attention to the recommendations of classical books like those of Dearden and Hofstede. Actual practice in the real world has always been, and continues to be, very diverse, but a trend towards using budgets mechanically and thus inducing different types of gaming has been almost a constant. Two dysfunctional practices along those lines even have a name: ratcheting and storming. Ratcheting consists in management automatically raising quantitative targets (say, sales) when the previous target has been achieved. This practice clashes with the spirit of a reasonable budgeting process, but at the same time, it is easy to predict what is going to happen: objectives will not be achieved to avoid having to face targets that are more difficult in the next period.

Storming consists of anticipating sales, say, that are supposed to take place in January, to December, if it looks as if the sales objective is not going to be met, thereby transferring the problem to the next period. This practice has been at the origin of many scandals, because every year the problem is bound to become bigger and, at the end, fake sales, fake reports or both are the only way to achieve targets. Of course, the opposite may also be done: if it looks like the yearly objectives are going to be met, or even surpassed, one may delay the recognition of some sales to make it easier to meet next year's targets. In both cases, we get a vicious circle that goes against the company objectives.

Hansen et al. (2003) provide a list of the following problems, taken from Neely et al. (2001):

1. Budgets are time-consuming to put together;

2. Budgets constrain responsiveness and are often a barrier to change;

3. Budgets are rarely strategically focused and often contradictory;

4. Budgets add little value, especially given the time required to prepare them;

5. Budgets concentrate on cost reduction and not value creation;

6. Budgets strengthen vertical command-and-control;

7. Budgets do not reflect the emerging network structures that organizations are adopting;

8. Budgets encourage gaming and perverse behaviors;

9. Budgets are developed and updated too infrequently, usually annually;

10. Budgets are based on unsupported assumptions and guesswork; 
11. Budgets reinforce departmental barriers rather than encourage knowledge sharing;

12. Budgets make people feel undervalued.

According to Libby and Lindsay (2010) “... some argue that the problems with fayolbudgeting stem from the way budgets are used (Horngren et al., 2004) while others argue that budgeting processes are fundamentally flawed (Hope and Fraser, 2003a)". But since the objective of Libby and Lindsay is to present empirical evidence with respect to budgeting practices, they do not analyze in depth the reasons people like Horngren have to justify their position; which is just what this paper intends to do next.

Let us, then, briefly examine each one of the problems suggested by Hansen et al. (2003) above.

Numbers (1) and (4) have to do with the cost of doing the budgets and the time to prepare them (which is part of the cost, of course). Naturally, the design of a budgetary system can be made more or less expensive depending on the circumstances; but the disproportion between cost and value added indicated by (4), when it happens, responds to a bad design. A good design does not add cost that is not compensated by additional value: simplifying budgeting procedures, when they do not add value is one of the classical principles expressed by Dearden and Hofstede.

Objections (2), (6), (7), (11) and (12) have to do with the structure and the relationships between people in the organization. But budgets by themselves cannot do such things. It is the people that act in the process that can do them or not. People feel undervalued when the hierarchical superiors make them feel so, not because of the budget. The way the budgets are done, mainly if they are done mechanically and without the active participation of the hierarchical superior may indeed make people feel undervalued; but , again, this goes directly against the spirit of the classical texts on budgeting. Doing things wrong does not make the tool useless or harmful.

Objection (10), of course, is a bad practice. All assumptions have to be supported; and, as we will see, budgeting is a good way to learn how to forecast better and how to meet the budgeted figures.

Objections (3), (5) and (9) are particularly bad practices in terms of budgeting: if a budget in not rooted in the critical success factors and the strategy, it will be worse than nothing, if it does not help to create value beyond its cost, a budget should be simplified, and if the business is very dynamic, they should be updated as frequently as needed. Other practices are simply bad practices. 
A particularly interesting objection is objection (8). This is very often argued; but we will attempt to show in our example below how whether this happens or not, depends on how the budgeting process is carried out. The management quality (or its lack thereof), and not the budget, is to be blamed if something like this happens.

Therefore, if done right, budgets do not have all those problems; and, thus, if they actually do, it must be because of bad management or misuse of the tool. Whether the budget itself "pushes" organizations into those practices even with good management would be something that would have to be proved by the accusation, not by the defense.

\section{Beyond budgeting}

However, and since the beginning of the $21^{\text {st }}$ Century, criticisms have gotten worse, both from the consulting world and from the academic world. From the first group, Jeremy Hope and Robin Fraser have been perhaps the sharper critics, for instance in an article whose title ("Who Needs Budgets", Hope and Fraser, 2003a) already suggests that budgets are useless. The expression "Beyond Budgeting" (Hope and Fraser, 2003b) has been their motto, suggesting that we should go beyond budgeting to something else. In one thing they are absolutely right: budgets cannot solve everything, and, thus, we have to go often beyond budgeting, but this does not mean that we can dispose of the budgets. Or, in other words, budgeting may have to be very often the starting point.

But their criticisms are nothing really new. They go back to the idea that budgets are rigid, help centralization, and are based on a "command and control" approach. And, taking advantage of the favorable tide of balanced scorecard, they propose a wider set of measures to evaluate performance.

Given today's advances in management tools, indices that are broader than the merely financial numbers, may indeed be, and often are, very useful. We have to be careful, though, because there are clear dysfunctional (or even perverse) consequences of performance measures when they are used mechanically and have an incentive payment automatically associated (Ridgeway, 1956; Rosanas \& Velilla, 2005; Cugueró-Escofet \& Rosanas, 2013 and 2016). Hence, eliminating the budget in order to introduce a wider set of performance measures is (a) simply ignoring what the budgeting processes can actually achieve, and (b) introducing a new tool that, if misused like the budgets are when some of the criticisms above are true, may be even more dangerous than the budget.

On the academic side, the best-known critic is Jensen (2001), but his criticisms go almost exclusively to the incentive systems based on receiving a reward if some (budgetary) goal 
is achieved, and nothing if it is not, perhaps with a linear increase beyond the budgeted goal. His proposal, basically, is that the reward should be linear from zero, i.e., that the goal should not even exist. The explicit problem of goal-setting (and of the rewards based on such goals) is more general, in fact, and is only indirectly related to the budgetary procedures.

Merchant's criticisms (2013) go along similar lines, using even stronger words, as can be seen in his title ("Companies Get Budgets All Wrong"), but in fact he goes back to the idea that firms need a richer set of performance measures and need to be more flexible. In fact, empirically, and in spite of the apparent success of the "beyond budgeting" expression and methods, most firms have not discarded their budgeting systems (Libby $\&$ Lindsay, 2010). Therefore, their arguments do not seem to have been very convincing, in spite of all the marketing they have had.

The (limited, I should add) success that they have had is to some extent surprising, because in fact in their analyses they ignore most of the factors that have been summarized in this paper in relation to the different objectives of budgeting and focusing almost only in the incentive system induced by goal-setting procedures. This is the reason why we want to finish this article with the analysis of a budgetary system that is useful, and that through an adequate budgetary process and an adequate management style, succeeds in doing the opposite to what the critics argue.

\section{The management control process}

The classical textbook treatment of the budgetary process is technical, descriptive and quantitatively oriented. It says (mistakenly, sometimes) that it begins with the marketing people preparing a sales forecast or budget. Mechanically, it seems only logical. Next, it continues in the different departments with a budget of costs and expenses, given the sales volume and perhaps production volume, ands it ends in the controller department putting everything together in the form of a "master budget", which consists mainly of the proforma financial statements. At most, it mentions that there is a 'negotiation process', that sometimes a 'budgetary slack' is introduced, and mentions some of the usual problems found in that area ('storming', 'ratcheting', and so on) merely as problems. And, thus, possible negative aspects of the budgetary process that are, implicitly again. inevitable. From an academic point of view, a clear example of the mechanistic approach that agency theory assumes in management control settings can be found in Heinle et al. (2014). In that paper, only two types of budgeting are considered: participative (i.e., bottom up) or 
non-participative (i.e., top down). Only extreme possibilities are taken into account: decisions are made either at the top and transmitted down the line; or else, they are made at the bottom and are accepted by the upper levels. Dialog and compromise are excluded. The previous attitudes of principal and agent that typically follow their experience with each other, and determines their willingness to cooperate, the organizational climate, the possible identification with the organizational objectives, the atmosphere of trust between them, and many other qualitative and behavioral variables are ignored too, consistently with the basic agency theory model. The management control process, thus, is stylized in what is actually is a caricature of what happens in reality: only a sequence of events is described, without human interaction. No wonder that many people want to get rid of it. Very few cases or textbooks describe real-world budgetary processes, often because, as we have argued, they are often inappropriately carried out. Doing a budget correctly, with the criteria analyzed above where simplicity is an important one, is a quite difficult endeavor. Next, I will try to summarize one, taken partly from a classic Harvard case, where this is done in some detail and comment on it ${ }^{1}$. A parallel example can be found in Vancil (1973, p. 80, “Company C"), although inevitably with some degree of simplification.

\subsection{Critical success factors}

First, in terms of the conceptual framework presented above, in order to design a budgetary process one has to identify the "critical success factors" for the company, given the industry and the strategy of the company. In this case, one could identify that what the company has to do well to survive and make a profit are essentially three things: good quality, good service (mainly in terms of delivery) and costs. Glass products are typically for customers that manufacture different types of liquids (all kinds of beverages, chemicals, perfumes, and so on), where the value of the glass receptacle that holds it is small compared with the value of the product itself; and they do not want to run the risk of a poor quality bottle ruining the product. Service (mainly in terms of delivery) is crucial as well. Imagine a producer of soft drinks in the middle of a hot summer: demand increases more than expected, and many bottles are needed to meet this demand. If this is true, then, the glass company has to have flexibility to deliver the glass product when it is needed. And for this purpose, and given the rigidities of the production process, it

\footnotetext{
${ }^{1}$ See Empire Glass Company, Harvard Business School, case 9-109-043
} 
needs to have a very accurate sales forecast and production scheduling that can later be adapted more easily to meet all the production constraints. Thus, this has to be a high priority of the budgetary process. Inventories are not the solution to the problem: they are expensive to carry and to store (essentially, you carry and store air...). As we will see, this can only happen if the budgetary process induces trust between bosses and subordinates.

\subsection{Top management involvement}

A second important aspect is the Hofstede principle that top management has to consider that the budgets are their tool to run the company, and therefore have to be involved in it from the very beginning. In the case cited before, the CEO starts the process by asking his divisional managers to submit preliminary estimates of sales and income for the next year, the capital requirements for the same year and an even rougher outlook for the two following years. The divisional managers do not have the time to go through a detailed analysis (which is going to be done only later) and thus they can base their estimates only on their first-hand knowledge of the business. Thus, this small beginning of the budgetary process has already the good property of submitting the management team to an "exam" every year for which they have to be prepared by knowing their business very well. If they do, they will get close to the final result of the budgetary process and this will nurture trust between the CEO and the first-line officers.

\subsection{A non-issue: participative budgeting}

Next, a technical staff goes to work in market research, based on the available statistics of the evolution of markets and the market trends and climate. This will provide a good check for the "real" sales budget, to be done next by the Sales division, and already gives the flavor of what the sales budget may look like at the end of the process.

The "real" sales forecast is prepared next with a "bottom up" approach. Not in a stylized way, but with a real dialog and discussion at the different hierarchical levels. Salespeople know their customers and their needs, and can attempt to predict what may happen with them next year, but may not know some market trends or the movements of a competitor, and so on, and thus they may be unnecessarily optimistic or pessimistic.

This point is crucial, because if this is done the wrong way, may drastically reduce the usefulness of the budgets. Suppose, for instance, that management responds to a forecast from the sales people by asking systematically for more (not an uncommon practice, 
certainly). Then, it would not be surprising to find that next year the sales people understate the amount they think they can sell; which may create really a vicious circle where the results are completely unrealistic. Dialog and negotiation have to result in something that is reasonable and acceptable to both parties; and if this does not happen at the end of the process, we may have created a monster for the next period.

Obviously, a "tolerant" management that accepts every proposal from the "bottom" without discussion may create an even worse problem: that of people not making any effort in order to improve the results. As usual, in Aristotelian terms, the virtue is in the middle. In fact, the budgeting process has to be used (1) to obtain an accurate sales forecast, which is necessary given production rigidities, and (2) as the instrument to create trust within the sales organizations between the different hierarchical levels. The two of them are crucial, but (1) cannot be obtained without (2). If mistrust installs, then we will have all types of gaming behavior like those included in the above criticisms. The attitude of the different levels of management towards their subordinates will be determinant to this respect.

The third important aspect is then that the "participative budgeting" issue vanishes in this context: all budgeting has to be participative from the point of view that subordinates have to be listened to, and all budgeting has to be to some extent "top-down" from the point of view of attempting to obtain better goals. The technical study done by a marketing research staff may be a good too for that purpose, with at least two consequences. First, that sometimes the marketing research study will indicate the line managers that they are perhaps too optimistic: this may happen, for instance when all customers (producers of soft drinks, for instance) believe that they will gain some market share from the others. Then, the forecast prepared the line people may be too optimistic, and the market study will indicate that: it is impossible for all the customers to grow, say, $4 \%$ next year if the total growth of the industry has been projected at, say, $2 \%$ only. If this never happens, it will be a clear indication on the part of the line managers that they engage in "ratcheting" or a related form of gaming; and trust between bosses and subordinates will go down the drain.

As we mentioned before, in the particular company cited, an accurate sales forecast was crucial for success; thus, once the discussion had ended, the sales forecast would receive the approval of the Top Management and would be complete. It would not be modified unless at the beginning of the period of its execution it became clear that market circumstances were different from the ones assumed in the budget. 


\subsection{Cost and expense decisions}

Production, so far, had not participated "formally" in the budget, although through informal relations they knew more or less what was going on. After the sales forecast was finished and approved, production plants would prepare: (1) a schedule of production; (2) a standard cost-based statement of direct production costs; and (3) a complete statement of all the fixed costs, including of course committed costs (about which no decision had to be made) and discretionary costs, that had to be the result of an always difficult decision. The production plants were considered profit centers, as a consequence of the critical success factors. If the results were not satisfactory, the plants' budgets, primarily the decisions on discretionary costs would have to be revised. Management's objective was not that of maximizing profit, was to obtain a reasonable profit that would satisfy the shareholders. For that purpose, if, in a given year profit was less than reasonable, the plants were asked to revise their budgets. Under no circumstances the sales budgets would be revised: if they were considered correct under the assumptions made at the beginning, it made no sense to revise the sales budgets upwards, the accuracy of the budgets being a crucial variable.

\subsection{The role of the controller}

A fifth issue is the role of the controller. The controller has to be of help in the technical, accounting aspects of the budget, not in filling out the figures. The production people may be very sophisticated engineers, but this does not mean that they are able to prepare appropriately an income statement. Non-accountants tend to mix cash inflows and cash outflows with accruals of different kinds in a meaningless way. For instance, in thinking that today's investments affects this year's income statement, or that postponing to next January the payment of some raw materials will increase profit for this year, and often forget that what is spent in some class of expenses cannot be spent in a different class. The controller has to be helpful in this, and perhaps in forecasting techniques or in variance analysis, but he should never produce the numbers of the budget. In the case we are using as an illustration (a conglomerate with many plants) the controller would visit every year every plant for a half a day. He would attempt to make sure they all started with shared hypotheses, see whether the plans every plant was making was in agreement with the plans of top management, and suggest possible modifications. Those modifications could suggest cuts if he thought that the bottom line was insufficient, or perhaps (in the opposite direction), with a long run view, increasing spending in some 
discretionary costs if the plan could afford it, but with no authority to say yes or no to any proposals of the plant.

Again, participative budgeting is a non-issue, since the information about what is necessary or not and to what extent a plant could benefit from an increase in a discretionary cost is something that necessarily has to come from the plant, while the bottom line that is satisfactory has to come from the Top Management.

\subsection{Putting the budget together and budget review}

Finally, at headquarters, and under the direction of the controller, the consolidation of the budgets from every division and analysis of the results would take place. If (again) the bottom line were not good enough, they would send the budget back to the plants so that they could reduce their expenses to meet the target.

Finally, the budget would be approved by Top Management.

During its execution, if management saw that some changes had happened in the environment that demanded a change in the budget, this change would be done; if this happened towards the end of the year, no change in the budget would take place. Notice that this procedure, poorly used, may induce rigidity; but wisely used, there is no reason why it should. A reasonable variance analysis after the fact that takes account of all these possible changes (for the better or for the worse) can take care of that.

\section{Discussion: good budgeting requires good management, based on an optimistic view of human beings}

The previous discussion was based on a specific case. In others, things may well be different, because the critical success factors may well be different as well. For instance, in some other cases, the sales effort may be crucial and production scheduling not that much (say, because of the convenience of having enough inventories), and, then, the budgetary process has to be designed with other objectives in mind and emphasizing other variables, but again with the spirit of achieving something that is worth to achieve.

The key point is then the quality of management, in budgeting like in anything else. The quality of good management has to be based on hard evidence (Pfeffer and Sutton, 2006) and on a sense of mission, i.e., having as the main objectives of the firm those of satisfying the (real, as opposed to perceived) needs of customers, and the real (again, as opposed to perceived) needs of the employees. This cannot be done in a purely mechanical way, which is what (implicitly) some academicians deem to wish, as seen in the papers quoted. 
Sumantra Ghoshal published in 2005 a posthumous paper which has possibly been his most influential one. In that paper, he criticized harshly an "ideology essentially grounded in a set of pessimistic assumptions about both individuals and institutions - a 'gloomy vision' (according to Hirschman, 1970) that views the primary purpose of social theory as one of solving the 'negative problem' of restricting the social costs arising from human imperfections".

These pessimistic assumptions lead to bad management and to the bad practices that have been briefly discussed in Section \#6: mechanical application of budgets, storming on the part of the "budgetees", ratcheting on the part of management, and so on. It is undeniable that these things happen, and that therefore all the criticisms about them are right. But they are not inevitable, if the organization is managed right.

In fact, as Ghoshal (2005) and Ghoshal and Moran (1996) have pointed out, the pessimistic assumptions of people being only self-interested and doing only what they think is good for them, may well be a self-fulfilling prophecy. In physics, if we believe that the behavior of, say, quarks is different from what it really is, this belief does not change in any way the behavior of the quarks. In contrast, in management, if we believe people behave a given way, we clearly increase the probability of their behaving that way, be it for the good or for the bad. If you assume that human beings are going to behave badly (in our case, paying attention only to their own rewards instead of doing what is "good" for the organization) they are likely to end up actually doing that. Pérez López (1991) called this phenomenon "negative learning", and is something that happens very often in organizations, in a context of a "control and command" management. When "no excuses are accepted" and the only thing management wants to see are "measurable results" (like, in the context of budgeting, achieving a sales target, a cost cut, or whatever), negative learning often occurs. The firm may end up achieving some short run objectives, but it will be at the cost of making it more difficult for the management to achieve the same objectives next time. Within a "control and command" context, employees learn what they have to do in order to protect themselves from being treated arbitrarily by management. And in a going concern that is supposed to last a long time, perhaps even forever, these practices will not facilitate the desired end.

Paradoxically, perhaps, budgets and variance analysis should be very useful (it may be their primary objective) in learning about the business, about the organization capabilities, about what can be expected and the likelihood of the unexpected, and so on. I began citing Fayol, and I want to go back to him now, because the word he used 
(prévoyance, or foresight) was intended to reduce, or eliminate altogether, surprises. From this point of view, we should do budgets to learn to do budgets better and avoid undesirable surprises. Of course, at a reasonable cost and making it as simple as possible.

\section{Conclusion}

Whether budgeting is or is not a good management tool is a pseudo-problem. In any organization, a budget can be useful, even extremely useful; but it has to be done in a context of good management practices, not in the context of a system that, on paper, is technically perfect, but is not understood by the line people involved. It has to be tailormade, depending on the specific circumstances of the environment, on the company's strategy, and coherent with the management style of the company. Many of the shortcomings (if not all) of the budgetary systems can be attributed to bad management practices.

Obviously, a budgetary system by itself cannot solve all the decision-making problems of a company, and may need additional variables to be controlled by other means. In other words, we often may have to go beyond budgeting, but almost always in the context of a thoughtfully designed budgetary system. 


\section{REFERENCES}

Anthony, R.N. (1965). Planning and Control Systems: A framework for Analysis. Boston, Massachussets, The Harvard Business School Press.

Anthony, R.; Dearden, J.; Vancil, R. (1972). Management Control Systems: Text, Cases and Readings, Second edition, Richard D. Irwin, Homewood, Illinois.

Barrett, E., Fraser, L., (1977). Conflicting Roles in Budgeting for Operations, Harvard Business Review, 55 (4) July/August.

Bruns, W., Waterhouse, J., (1975). Budgetary Control and Organization Structure, Journal of Accounting Research, 13(2), 177-203.

Cugueró-Escofet, N., Rosanas, J. M. (2013). The Just Design and Use of Management Control Systems as Requirements for Goal Congruence. Management Accounting Research, 24(1), 23-40.

Cugueró-Escofet, N., Rosanas, J. (2016, forthcoming). The Ethics of Metrics: Overcoming the Dysfunctional Effects of Performance Measurements through Justice, Journal of Business Ethics.

Dearden, J. (1962). Cost and Budget Analysis, Englewood Cliffs, New Jersey, PrenticeHall.

Fayol, H. (1916). Administration Industrielle et Générale: Prévoyance, Organisation, Commandement, Coordination, Contrôle, Paris, Dunod,.

Ghoshal, S., (2005). Bad Management Theories are Destroying Good Management Practices. Academy of Management Learning \& Education, 4 (1), 75-91.

Ghoshal, S., Moran, P. (1996). Bad for Practice: A Critique of Transaction Cost Theory. Academy of Management Review, 21(1), 13-47.

Gordon, M. and Shillinglaw, G., (1964). Accounting: a Management Approach, Third Edition, Homewood, Illinois, Richard D Irwin.

Flamholtz, E., (1983). Accounting, Budgeting and Control Systems in Their Organizational Contexts: Theoretical and Empirical Perspectives, Accounting, Organizations and Society, 8, 153-169.

Hansen, S., Otley, D., and Van der Stede, W., (2003). Practical Developments in Budgeting: An Overview and Research Perspective. Journal of Management Accounting Research, 15, 95-116.

Hansen, S., Van der Stede, W., (2003). Multiple facets of Budgeting: an Exploratory Analysis, Management Accounting Research, 15, 415-439.

Heinle, M., Ross, N., Saouma, R., (2014). 'A Theory of Participating Budgeting', The Accounting Review, 89(3), 1025-1050. 
Hirschman, A., (1970). The search for paradigms as a hindrance to understanding, World Politics, March.

Hofstede, G., (1968). The Game of Budget Control, London, Tavistock.

Hope, J. and Fraser, R., (2003a). 'Who Needs Budgets', Harvard Business Review, 81(2) 108-115, February.

Hope, J. and Fraser, R. (2003b). New Ways of Setting Rewards: The Beyond Budgeting Model, California Management Review, 45 (2), Winter.

Jensen, M., (2001). 'Corporate Budgeting is Broken. Let's Fix It', Harvard Business Review, 79 (10), 95-101.

Lawrence, P, and Lorsch, J., (1967). Organization and Environment, Homewood, Illinois, Richard D. Irwin.

Libby, T., Lindsay, R.M., (2010). Beyond Budgeting or Budgeting Reconsidered? A Survey of North-American Budgeting Practice, Management Accounting Research, 21, 56-75.

Merchant, K., (2013). 'Companies Get Budgets All Wrong', The Wall Street Journal, http://www.wsj.com/articles/SB10001424127887323873904578571810482331202, accessed February, 11, 2016.

Neely, A., M. R. Sutcliff, and H. R. Heyns. (2001). Driving Value Through Strategic Planning and Budgeting. New York, NY: Accenture.

Otley, D., (1980). 'The Contingency Theory of Management Accounting: Achievement and Prognosis', Accounting, Organizations and Society, 5(4), 413-428.

Otley, D., and Berry, A., (1980). 'Control, Organisation and Accounting', Accounting, Organizations and Society, 5(2), 231-244.

Pérez López, J.A. (1991) Teoría de la Acción humana en las organizaciones, Madrid, Ediciones Rialp.

Pfeffer, J., Sutton, R., (2006). Hard Facts, Dangerous Half-Truths \& Total Nonsense: Profiting from Evidence-Based Management. Boston, Mass., Harvard Business School Press.

Ridgeway, V (1956). Dysfunctional Consequences of Performance Measurements, Administrative Science Quarterly, 1(2), 240-247.

Rosanas, J. \& Velilla, M., (2005). The Ethics of Management Control Systems: Developing Technical and Moral Values. Journal of Business Ethics, 57: 83-96

Shillinglaw, G., and Meyer, P., (1983). Accounting: a Management Approach, $7^{\text {th }}$ Edition, 1983, Homewood, Ill, Richard D. Irwin. 
Vancil, R. F. (1973). 'What kind of management control do you need?' Harvard Business Review, 51 (2) March-April. 